\title{
Review
}

Journal of Innate

Immunity
J Innate Immun 2013;5:367-376

DOI: $10.1159 / 000350612$
Received: November 27, 2012

Accepted after revision: March 12, 2013

Published online: April 30, 2013

\section{Control of Myeloid Cell Trafficking in Resolution}

\author{
Lucy V. Norling Mauro Perretti
}

The William Harvey Research Institute, Barts and The London School of Medicine and Dentistry, London, UK

\section{Key Words}

Apoptosis · Efferocytosis · Annexin A1 - Resolvin .

G-protein-coupled receptor

\begin{abstract}
Following tissue injury or microbial invasion, neutrophils are robustly recruited to inflammatory loci, which is a hallmark of the host inflammatory response. This event initiates a series of processes required to activate resolution, including recruitment of monocytes, clearance of microbes, cellular debris and apoptotic neutrophils, the egress of phagocytes and, ultimately, regain of tissue homeostasis. Substantial evidence now signifies that resolution of inflammation is a highly coordinated, active process dictated by the spatial-temporal generation of proresolving mediators that act on specific receptors to modulate cell and tissue reactivity. This review will focus on the mediators, targets and pathways initiated to orchestrate resolution. Importantly, disruption of the key processes involved in inflammatory resolution could result in delayed restoration of tissue homeostasis, leading to fibrosis and/or persistent inflammation.
\end{abstract}

Copyright $\odot 2013$ S. Karger AG, Basel

\section{Active Termination of Inflammation: Mediators and Their Actions on Leukocytes}

It is now widely recognized within the scientific community that the host immune response to inflammation does not simply dissipate, but is actively switched off by engagement of proresolving pathways [1]. In recent years, a repertoire of mediators has been uncovered that fall under this umbrella of effectors of resolution. These proresolving mediators include canonical mediators such as cortisol and adenosine (which will be little discussed here) as well as more recently identified lipid, protein and peptide agonists such as the lipoxins (LXs), resolvins (Rvs), annexin A1 (AnxA1) and melanocortins (MCs), amongst several others. It is important to define that a proresolving mediator stimulates and activates endogenous pathways to regulate cellular trafficking, modulate myeloid cell lifespan and phenotype, and enhance tissue restoration to accelerate resolution; as such, a proresolving mediator is not equivalent to an anti-inflammatory mediator, which acts as a blocker of specific pathways or enzymes involved in the initiation of an inflammatory response. Table 1 summarizes the proresolving effects activated by effectors of resolution on myeloid cells. Thus, in contrast to current anti-inflammatories that typically target the 'heating-up' period of the immune response, new therapeutics based on proresolution mediators would accelerate the way our body naturally regulates an inflammatory reaction, prompting the regain of physiological tissue function.

LXs were the first anti-inflammatory and proresolving lipid mediators recognized that signal the resolution of acute inflammation [2]. During the time course of inflammation, mediator generation switches from arachidonate-derived eicosanoids, such as prostaglandins and leukotrienes, to anti-inflammatory LXs [3] and omega-3 eicosapentaenoic acid and docosahexaenoic acid-derived

\section{KARGER}

E-Mail karger@karger.com

www.karger.com/jin
(C) 2013 S. Karger AG, Basel

$1662-811 \mathrm{X} / 13 / 0054-0367 \$ 38.00 / 0$
Dr. Lucy V. Norling or Dr. Mauro Perretti

Centre for Biochemical Pharmacology, William Harvey Research Institute Barts and The London School of Medicine Charterhouse Square, London EC1M 6BQ (UK)

E-Mail l.v.norling@qmul.ac.uk,m.perretti@qmul.ac.uk 
Table 1. Summary of the major proresolving effects activated by effectors of resolution on myeloid cells

\begin{tabular}{|c|c|c|}
\hline Proresolving property & Resolution agonists & References \\
\hline$\downarrow$ Neutrophil migration & $\begin{array}{l}\text { adenosine, AnxA1 and N-terminal peptide Ac2-26, cortisol, DHEA metabolites, } \mathrm{E}_{2}, \mathrm{LXA}_{4} \text {, } \\
\text { MaR1, } \alpha \text {-MSH, } \gamma \text {-MSH PD1, RvD series, RvE series }\end{array}$ & $3,8,68-74$ \\
\hline$\uparrow$ Microorganism phagocytosis & AnxA1, Ac2-26, chemerin-derived peptides, $\mathrm{LXA}_{4}, \mathrm{MaR} 1, \alpha-\mathrm{MSH}, \mathrm{RvD}$ series, RvE series & $9,30,71,78$ \\
\hline$\uparrow$ Monocyte recruitment & $\mathrm{LXA}_{4}, \mathrm{LXB}_{4}, \mathrm{Ac2}-26$ and shorter peptides & 17,18 \\
\hline$\rightarrow$ Macrophage skewing & adenosine, RvD1 & 36,37 \\
\hline$\uparrow$ Phagocyte exit to lymphatics & $\mathrm{LXA}_{4}, \mathrm{RvE} 1, \mathrm{PD} 1$ & 30 \\
\hline
\end{tabular}

DHEA metabolites = Docosahexaenoyl ethanolamide derivates, e.g., 10,17-diHDHEA and 15-HEDPEA; $\mathrm{E}_{2}=$ estradiol; MaR1 = maresin-1 (omega-3 derivative, docosahexaenoic acid derived); $\mathrm{MSH}=$ melanocyte-stimulating hormone; PD1 = protectin D1 (omega-3 derivative, docosahexaenoic acid derived); $\mathrm{Rv}=$ resolvin (omega-3 derivative, E series, eicosapentaenoic acid derived, D series, docosahexaenoic acid derived); LysoPS = lysophosphatidylserine.

Rvs, protectins and maresins [4]. These local chemical mediators (autacoids) are biosynthesized via distinct cellular or transcellular enzymatic pathways yielding unique stereospecific molecules [for a review, see ref. 4].

AnxA1 is a glucocorticoid-regulated protein that exerts a variety of proresolving properties, spanning from inhibition of myeloid cell extravasation to modulation of white blood cell lifespan in the inflamed tissue, from phagocytosis and efferocytosis (containment and clearance) to instruction of the adaptive immune system [5]. Work in the last decade has not only allowed the definition of these biological properties but also defined AnxA1 biology distinctly from the physiopharmacological control exerted by glucocorticoids. As an example, migrated neutrophils upregulate their AnxA1 content and release [6] to promote specific proresolving actions (table 1). Macrophages can also release AnxA1 to attain the same biological functions [7]: these events can occur both in a glucocorticoid-independent and -dependent fashion.

MCs are another group of less en-vogue endogenous proresolving mediators; these include $\alpha$ - and $\gamma$-melanocyte-stimulating hormone and adrenocorticotrophin. These polypeptides block neutrophilic infiltration $[8,9]$ and the production of proinflammatory cytokines from target cells [for a review, see ref. 10], yet also activate proresolving processes including the induction of heme oxygenase 1 [11] via signaling through specific MC receptors as further discussed vide infra.

As elegantly depicted in a recent review by Soehnlein and Lindbom [12], a self-limited inflammatory reaction can be categorized into 4 distinct phases: (1) resident macrophages signal neutrophil extravasation; (2) neu- trophil secretion products recruit monocytes; (3) phagocytes release mediators to block further neutrophil influx, and (4) reprogrammed macrophages restore homeostasis. Initiation of the inflammatory response (phase 1 above) will be extensively covered by other articles within this special issue and will not be discussed in detail herein.

Distinct mechanisms are in place to recruit classical inflammatory versus nonclassical patrolling/resident monocytes to an inflammatory site. These two subsets are distinguished by their expression levels of chemokine receptors, most notably, $\mathrm{CCR} 2^{-} \mathrm{CX}_{3} \mathrm{CR} 1^{\text {hi }}$ versus $\mathrm{CCR} 2^{+} \mathrm{CX}_{3} \mathrm{CR} 1^{\text {low }}$ in mice [13] - or $\mathrm{CD} 14^{+} \mathrm{CD} 16^{+}$versus $\mathrm{CD} 14^{\mathrm{hi}} \mathrm{CD} 16^{-}$in humans [14] - for patrolling versus inflammatory cells, respectively. Patrolling monocytes crawl along the vascular endothelium and rapidly exit the bloodstream upon sensing signs of inflammation or infection, whereupon they produce cytokines that contribute, together with a plethora of other proinflammatory and danger signal mediators, to the initiation of an inflammatory response. Comparatively, classical inflammatory monocytes typically enter the tissue after neutrophils and are the predominant leukocyte subtype at 48$72 \mathrm{~h}$ in experimental peritonitis or pleurisy reactions, and differentiate locally into inflammatory macrophages or dendritic cells [14].

Neutrophils are equipped with several types of intracellular granules, which contain receptors, cell adhesion molecules and proteases that can be rapidly mobilized upon activation, allowing prompt and efficient innate effector functions [15]. During diapedesis, neutrophils liberate proteinases such as cathepsin G and proteinase 3, which not only facilitate neutrophil transmigration, but 
also activate the endothelium. These mediators, along with azurocidin and the cathelicidin peptide LL-37 play important roles in recruiting classical inflammatory monocytes [16]. Interestingly, some of these cellular responses are mediated via a family of formyl peptide receptors (FPRs) that are also targeted by proresolving mediators and will be discussed vide infra. $\mathrm{LXA}_{4}$ and $\mathrm{LXB}_{4}$ are potent stimuli for human monocyte chemotaxis and adhesion [17]. Although this study predates the distinction of monocyte subtypes, these autacoids recruit monocytes in a nonphlogistic manner without causing release of proinflammatory mediators or reactive oxygen species production.

It is interesting how the same biological property of promoting nonphlogistic monocyte recruitment is emerging also for AnxA1 (unpublished) and AnxA1-derived peptides [18], the latter feasibly produced at the site of inflammation by the activity of serine proteases such as proteinase 3 or elastase [19] that are released as part of the trafficking process. Of interest, the central role played by AnxA1 in this context is also evident from its release by necrotic neutrophils, with the protein acting as a fail-safe signal [18] and possibly also able to promote monocyte recruitment to aid in debris removal and clearance. Additional properties of AnxA1-derived peptide Ac2-26 include the promotion of neutrophil chemokinesis [20], apoptosis [21] and efferocytosis [7] as well as monocyte recruitment [18]. In the latter case, peptide Ac2-26 is more efficacious than shorter peptides generated from the $\mathrm{N}$-terminal domain of AnxA1 by the activity of metalloproteases, indicating perhaps the existence of a hierarchy with the sequential engagement of specific proteolytic activities. The actions of highlighted proresolving mediators are reviewed in table 1 and figure 1 .

A common feature of these endogenous proresolving mediators is that they act essentially as brake signals to circumvent neutrophil-mediated tissue injury, by limiting neutrophil adhesion, diapedesis and chemotaxis [1]. Whilst the molecular mechanisms governing neutrophil recruitment and directional movement have been extensively investigated over the last few decades (see other reviews in this issue), the signals curtailing neutrophil migration are less well characterized. Signaling analysis has indicated that a dynamic balance between two canonical mitogen-activated protein kinases, extracellular signal-related kinase (ERK) and p38, controls neutrophil arrest and locomotor activity in response to the end-target chemoattractant formyl Met-Leu-Phe [22]. Detailed analyses showed G-protein-coupled receptor kinase 2
(GRK2) mediates the stop signal for chemotaxis via phosphorylation, internalization and desensitization of FPR1. The migrational response to formyl Met-Leu-Phe can be further dissected using specific mitogen-activated protein kinase inhibitors. Inhibition of p38 enhanced the stop signal, whereas inhibition of ERK (or activation of p38) overcame the arrest signal and warranted chemotaxis. Liu et al. [22] discovered that p38 acts as a GRK that phosphorylates the carboxy terminal of FPR1 at $\mathrm{Ser}^{342}$, which is a distinct site to GRK2, yet prevents FPR1 from interacting with GRK2 and thus blocking receptor internalization to permit sustained migration. The signaling pathways initiated downstream of FPR2/ALX that block neutrophil chemotaxis yet stimulate monocyte recruitment in response to the proresolving agonists AnxA1 and $\mathrm{LXA}_{4}$ are likely to be divergent. For example, $\mathrm{LXA}_{4}$ blocks actin polymerization and downregulates $\mathrm{CD} 11 \mathrm{~b}$ expression on polymorphonuclear leukocytes (PMN), inhibiting chemotaxis and reducing adhesion without inducing $\mathrm{Ca}^{2+}$ mobilization, whereas in monocytes, $\mathrm{LXA}_{4}$ triggers intracellular $\mathrm{Ca}^{2+}$ release and promotes adhesion $[23,24]$. Thus, it is likely that cell-specific, pertussis toxin-sensitive G-protein subtypes couple to the intracellular domain of ALX/FPR2, allowing divergent downstream signaling, and hence, different cellular responses [25]. It is now appreciated that $\beta$-arrestins are not only involved in receptor desensitization and internalization but may also act as multifunctional adaptor proteins that modulate a number of signaling networks [26]. Therefore, it is plausible that in different myeloid cells, proresolving mediators might exhibit biased agonism towards G-protein- or $\beta$-arrestin-mediated signaling. $\mathrm{LXA}_{4}$ and $\mathrm{RvD} 1$ recruit $\beta$-arrestin in a concentration-dependent manner in cells stably expressing GPR32 or ALX/FPR2, as demonstrated using a G-protein-coupled receptor (GPCR)- $\beta$-arrestin-coupled system to monitor receptor-ligand interaction [27]; whether there is $\beta$-arrestin-biased agonism in different myeloid cells remains to be determined.

An interesting twist has recently been reported for a specific myeloid cell, the eosinophil. Eosinophils are typically associated with allergic diseases or parasitic infections, yet Yamada et al. [28] reported that depletion of eosinophils led to augmented neutrophil influx and reduced phagocyte efflux to the draining lymphatics in a model of peritonitis. Of relevance, this lack of resolution in acute peritonitis was associated with diminished 12/15-lipoxygenase-derived lipid mediators including protectin D1. Recent studies indicate that eosinophils also produce another mediator of resolution, RvE3, to aid 


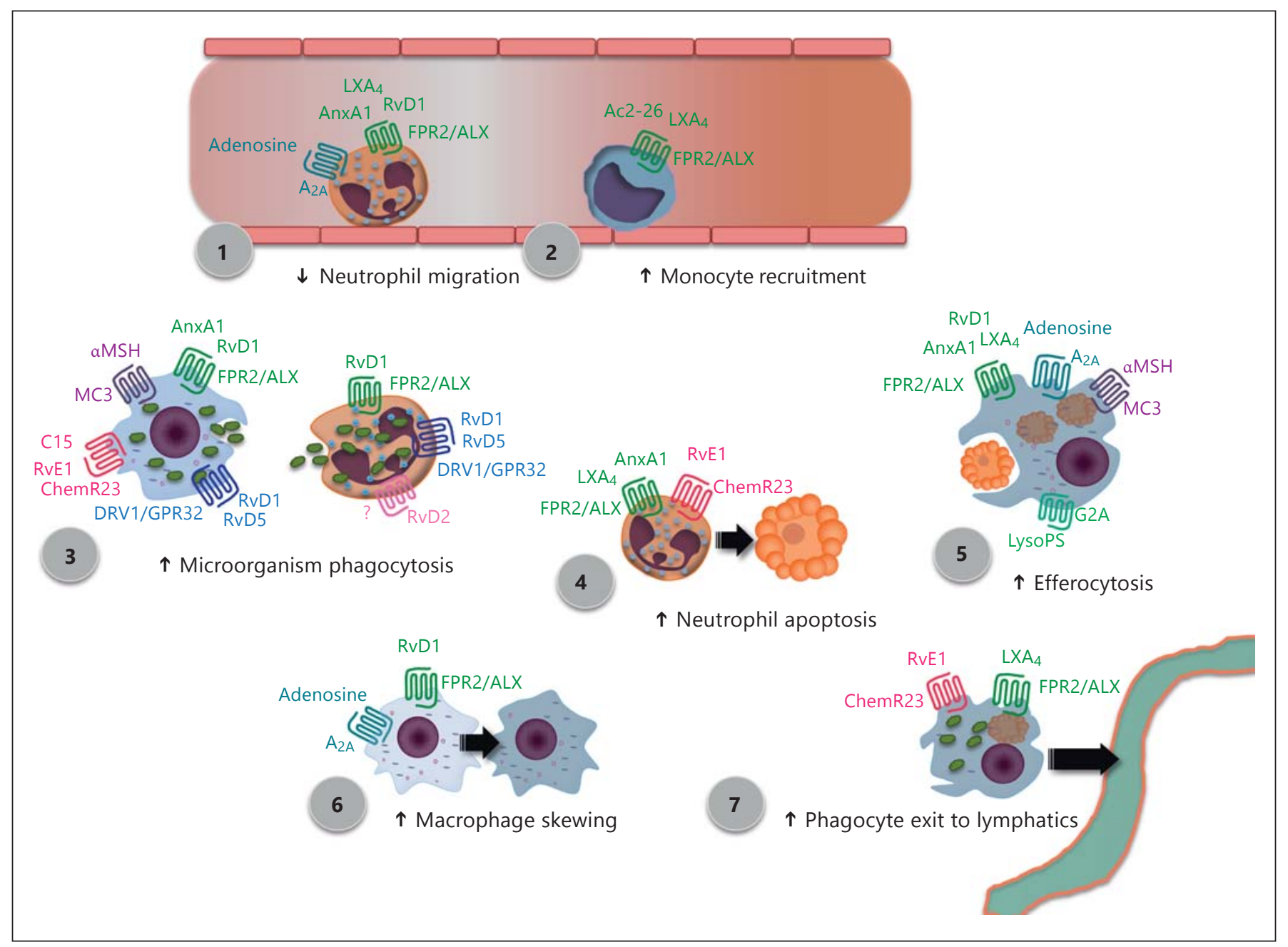

Fig. 1. Key protective actions of proresolving mediators on myeloid cells stem downstream agonism at specific GPCRs. During inflammation, a number of endogenous anti-inflammatory and proresolving mediators are generated locally and act via specific GPCRs to initiate resolution. Proresolving mediators such as AnxA1, RvD1 and $\mathrm{LXA}_{4}$ (that signal via FPR2/ALX), and adenosine (via $\mathrm{A}_{2 \mathrm{~A}}$ ) potently block further neutrophil migration (1). $\mathrm{LXA}_{4}$ as well as AnxA1 peptides, including peptide Ac2-26 and shorter peptides, increase monocyte recruitment to aid in microbial/debris removal

resolution [29]; whether this effect is indirect and mediated by an intermediate resident cell type such as the macrophage remains to be determined.

During the final stages of an inflammatory response, exudate tissue leukocytes either die locally (preferably by apoptosis) and are cleared by phagocytes, or leave the tissue by egress to the draining lymphatics or systemic recirculation. RvE1, $\mathrm{LXA}_{4}$ and protectin $\mathrm{D} 1$ are able to enhance the number of phagocytes carrying ingested zymo-
(2). A common feature of these protective mediators is containment and clearance of microorganisms (3); the chemerin peptide $\mathrm{C} 15$ signals via ChemR23 to mediate this response. Some of these mediators are also known to enhance neutrophil apoptosis (4), as well as their subsequent uptake via macrophages (5). Macrophage efferocytosis is known to skew macrophages towards a healing phenotype to assist with the restoration of tissue homeostasis; this process can also be induced by adenosine and Rvs (6). $\mathrm{LXA}_{4}$ and $\mathrm{RvE} 1$ also augment phagocyte egress to draining lymph nodes (7). 
Table 2. A selection of proresolving GPCRs active on myeloid cells

\begin{tabular}{|c|c|c|c|}
\hline $\begin{array}{l}\text { GPCR acronym } \\
\text { (G-protein subtype) }\end{array}$ & Endogenous proresolving agonists & Myeloid cell expression & References \\
\hline FPR2/ALX (Gi) & $\mathrm{LXA}_{4}$, epi-LXA 4 , AnxA1, RvD1 & PMN, Mo, MØ, eosinophil, microglia & $23,24,53$ \\
\hline $\mathrm{A}_{2 \mathrm{~A}}, \mathrm{~A}_{2 \mathrm{~B}}(\mathrm{Gs})$ & adenosine & PMN, Mo, MØ & 37,74 \\
\hline CB2 (Gi) & anandamide, DHEA & MØ, microglia & 72 \\
\hline GPR30 (Gs) & estrogen & $\mathrm{M} \varnothing$ & 87 \\
\hline $\mathrm{MC1}(\mathrm{Gs})$ & $\mathrm{ACTH}, \alpha-\mathrm{MSH}$ & PMN, MØ, eosinophil, basophil & 10,88 \\
\hline MC3 (Gs) & $\mathrm{ACTH}, \alpha-\mathrm{MSH}, \gamma-\mathrm{MSH}$ & MØ, exudated PMN & 10,89 \\
\hline G2A (Gs) & Lyso-PS & $\mathrm{PMN}, \mathrm{M} \varnothing$ & 90 \\
\hline GPR120 (Gq/11) & DHA and EPA & PMN, Mo, MØ & 91 \\
\hline
\end{tabular}

epi-LXA $4=$ Aspirin-induced epimer of $\mathrm{LXA}_{4} ; \mathrm{Mo}=$ monocyte; $\mathrm{M} \emptyset=$ macrophage $\mathrm{CB}=$ cannabinoid receptor; DHEA = docosahexaenoyl ethanolamide; SST = somatostatin receptor; DRV = resolvin D series receptor; GPR = orphan receptor; $\mathrm{ACTH}=$ adenocorticotrophin; $\mathrm{MSH}=$ melanocyte-stimulating hormone; Lyso-PS = lysophosphatidylserine; DHA = docosahexaenoic acid; EPA = eicosapentaenoic acid.

however, we now know that this is a far too simplistic view. Recently, an extensive transcriptome analysis of murine macrophages during the resolution phase of zymosan peritonitis revealed many overlapping aspects of both subtypes, suggesting that macrophages exhibit substantial plasticity during inflammation [31]. Efficient efferocytosis is essential for resolution; this process is a dynamic and rapid phenomenon to avoid secondary necrosis of the apoptotic neutrophil and perpetuation of tissue damage [32], as well as to promote reprogramming macrophages to a 'healing' phenotype. Effectors of resolution (such as $\mathrm{LXA}_{4}$ ) are able to induce neutrophil apoptosis to accelerate resolution [33], promote efferocytosis [34, 35] as well as skew macrophages towards an M2 phenotype and reduce proinflammatory cytokine generation (as with RvD1) [36]. Adenosine also induces macrophage reprogramming, augmenting arginase 1 and tissue inhibitor of matrix metalloproteinase 1 expression [37]. Recent data indicate that low $\mathrm{CD} 11 \mathrm{~b}$ expression correlates with the propensity of macrophages to emigrate to the lymphatics [38], and matrix metalloproteinase-mediated CD11b shedding promotes their efflux [39]. Mice treated with proresolving lipid mediators RvD1/RvE1, or with dexamethasone, during experimental peritonitis have significantly more CD11b ${ }^{\text {low }}$ macrophages, implicating another means by which mediators of resolution may control postexudate phagocyte trafficking and differentiation [38].

Effectors of the Resolution of Inflammation

\section{Active Termination of Inflammation: Proresolving Receptors}

From a pharmacological perspective, appreciation of the resolution of inflammation as an investigative area for drug discovery programs requires a detailed characterization of the receptor targets that are engaged by proresolving mediators. Here, we will focus on a subset of antiinflammatory GPCRs as effectors on resolution. In most cases, the $G$ protein coupled to the inhibitory receptor is an inhibitory $G$ protein or a $G$ protein associated with adenylate cyclase (table 2).

AnxA1 and peptides derived from its N-terminal domain bind to FPR2/ALX, a member of the FPR family of receptors, in transfected cells as well as in human PMN and compete with other known ligands [40]. Subsequent research demonstrated that the N-terminal peptide Ac226 signals via both FPR1 and FPR2/ALX [41, 42] and retains the ability to promote leukocyte detachment in Fpr1 null mice corroborating in vitro data that mouse ortholog(s) of human FPR2/ALX might be the candidate proresolving receptor [43]. In addition to a range of protein/peptide agonists, FPR2/ALX conveys the biological functions of high-affinity endogenous lipid ligands, including the already discussed $\mathrm{LXA}_{4}$ and RvD1, as well as their aspirin-triggered epimers. Using tritiated $\mathrm{LXA}_{4}$, specific binding sites were determined on human PMN, with a notable $K_{d}=0.5 \mathrm{nM}$ [44]. Chimeric receptors were 
generated to determine binding sites for $\mathrm{LXA}_{4}$, using receptors with opposing functions, namely ALX/FPR2 and $\mathrm{BLT}_{1}$ (a leukotriene $\mathrm{B}_{4}$ receptor), revealing that the seventh transmembrane segment and third extracellular loop are required for high-affinity binding [45]. Using this receptor-cloning strategy, distinct binding sites for peptide versus non-peptide ligands were identified within ALX/FPR2 likely explaining the diversity of ligands that recognize and signal via this single GPCR. A similar approach using FPR1 and FPR2/ALX chimeras was recently utilized to identify the binding sites for AnxA1 [46]: these results indicated that the $\mathrm{N}$-terminal domain of FPR2/ALX was sufficient for rapid downstream $\mathrm{Ca}^{2+}$ mobilization and ERK phosphorylation, whereas the second extracellular loop was necessary for gene activation and sustained AnxA1 responses. Therefore, the small lipid, the large protein and the shorter peptides that are generated from the N-terminal region of AnxA1 interact with distinct receptor domains to generate distinct downstream signals to modulate cell phenotype. It should not go unnoticed that FPR2/ALX is also the receptor for protein ligands that activate myeloid cells (for instance in terms of chemotaxis or chemokinesis) [24], a prime example being LL-37 we briefly mentioned above that engages FPR2/ALX to promote recruitment of inflammatory monocytes [16], nurturing the obvious question of how this receptor operates on the myeloid cell surface and whether it can engage distinct partners in a ligand-biased fashion. Future work will surely clarify this important aspect of the biology of this intriguing receptor.

In the same vein, there is need for further investigations regarding the mouse ortholog of human FPR2/ ALX. Thus, Dufton et al. [47] have described the first animal colony lacking mouse Fpr2 (along with Fpr3, which together are thought to represent human FPR2/ALX), reporting loss of anti-inflammatory effects by AnxA1 and $\mathrm{LXA}_{4}$. In addition, in some models (but not all), these mice displayed augmented inflammatory responses indicative of 'an anti-inflammatory nature' of this receptor [47]. A mouse colony generated with a different strategy was subsequently described by Chen et al. [48], with a phenotype suggestive of 'a pro-inflammatory nature' for Fpr2 since, in models of allergic airway inflammation, these mice were unable to mount a proper inflammatory reaction. It is plausible that the distinct strategies to nullify the receptor may underlie these apparent discrepancies $[47,48]$ and that, in rodents, human FPR2/ALX is genuinely represented by both mouse Fpr2 and Fpr3. On the other hand, a subsequent report by Chen et al. [49] suggests that the phenotype of the null mice could also be disease/organ specific. Using a model of dextran sulfate sodium-induced colitis, Fpr2 null mice exhibit exacerbated inflammation, colon thickening and shortening and significantly reduced survival rates, thus emphasizing the anti-inflammatory role for Fpr2. In any case, we also note that pharmacological delivery of FPR2/ALX agonists elicits tissue protection in antigen plus endotoxin-induced allergy by inhibiting dendritic cell infiltration, migration and maturation as well as blocking Th1 and Th17 polarization and protects from endotoxin-induced lung neutrophilia [50], pointing towards a true inhibitory function for the receptor also during lung inflammatory reactions. Of interest, FPR2/ALX agonists are also protective in other models of complex disease such as those mimicking sepsis [51].

Recently, two GPCRs for RvD1 were identified using a GPCR $\beta$-arrestin-coupled system, namely FPR2/ALX and orphan receptor GPR32 (newly termed 'DRV1') [52] on human leukocytes [53]. Compared to $\mathrm{LXA}_{4}, \mathrm{RvD1}$ specifically binds with high affinity to human PMN with a $\mathrm{K}_{\mathrm{d}}=0.2 \mathrm{nM}$. Competition binding experiments revealed that RvD1-specific binding was partially displaced by $\mathrm{LXA}_{4}$ (approximately 60\%), whilst no competition was observed with the AnxA1 peptide Ac2-12, supporting the notion of independent peptide/lipidbinding sites [53], a finding corroborated by the chimeric experiments of Bena et al. [46]. We recently investigated which of these RvD1 receptors signals to limit human neutrophil recruitment. Low RvD1 concentrations (nM) appeared to be DRV1/GPR32 specific, and increased concentrations elicited FPR2/ALX-dependent responses [54]. An interesting dichotomy emerged when neutrophil surface expression of these receptors was monitored: FPR2/ALX, but not DRV1/GPR32, membrane levels increased following cell activation with proinflammatory stimuli, a process secondary to secretory vesicle mobilization. We proposed that in human neutrophils, DRV1/GPR32 may play a homeostatic role, transmitting signals for low concentrations of RvD1, whereas FPR2/ALX is rapidly increased upon leukocyte activation to counter-regulate overzealous neutrophil recruitment. Accordingly, FPR2/ALX surface expression is elevated on human blister exudate PMN [55], further supporting the notion that this receptor can be rapidly mobilized on the cell surface as part of a counter-regulatory process. Thus, accumulating evidence implicates FPR2/ALX as a stereoselective yet multirecognition receptor that modulates the host immune response. 


\section{Modulation of Proresolving Receptor Expression}

An important yet understudied aspect in resolution is the 'flexible and rapid' adaptation of the host response towards the termination of inflammation and regain of tissue function. Whilst this can be achieved by the synthesis and release of proresolving mediators, another possible checkpoint may be at the level of receptor expression. Above, we have discussed the distinct nongenomic regulation of FPR2/ALX on the neutrophil cell surface, but it should also be noted that FPR2/ALX and DRV1/GPR32 are upregulated on monocytes (24- to 48-hour time scale) following exposure to zymosan particles or granulocyte macrophage colony-stimulating factor [53]. Thus, proresolving receptors are also upregulated through a process of promoter activation and gene induction. Along this vein, recent studies have examined FPR2/ALX promoter activity and found that $\mathrm{LXA}_{4}$ enhances the transcription of this receptor, in a forward feedback circuit [56]. In the context of MC receptors (GPCRs that convey the antiinflammatory and proresolving activities of adrenocorticotrophin and $\alpha$-melanocyte-stimulating hormone) [57], we have observed high and relatively stable expression of $\mathrm{MC}$ receptor type 1 (MC1) in macrophages, synovial tissue and subendothelial tissue in the mesenteric vasculature, with little expression of the MC3 receptor. However, upon application of an insult such as an ischemia-reperfusion procedure [8] or induction of joint arthritis [58], a marked upregulation of MC3 gene product occurred, with $\mathrm{MC1}$ remaining stable. We postulate that in these settings, MC3 mRNA is overexpressed in the affected tissue not only in view of the marked influx of myeloid cells, but also through genuine gene promoter activation, and that this is part of a homeostatic process aiming at directing the host response through resolution pathways. Similar observations have been obtained for mouse Fprl and Fpr2/3 in two distinct organs/tissues, such as the arthritic joint [59] and the emphysema lung [60]. In humans, smokers and individuals with emphysema have elevated levels of FPR2/ALX on peripheral blood neutrophils [61, 62], and elevated levels of FPR2/ALX are detected in synovial tissue biopsies of rheumatoid arthritis compared with osteoarthritis patients [63].

We propose that future research will investigate the modulation of the promoter activity of specific proresolving receptors and that this could represent an innovative strategy to rebalance uncontrolled inflammatory pathologies. Similarly, it will not be inconceivable that specific pathologies, from vascular diseases to those of the gut or the joint, could be associated with single nucleotide poly-

Effectors of the Resolution of Inflammation morphisms of coding regions yielding functional changes in the biology of proresolving receptors. Although in their infancy, a few reports have recently emerged, indicating an association between alterations in proresolving receptor expression levels on myeloid cells and human pathologies. Simiele et al. [56] have observed a single nucleotide polymorphism in the FPR2/ALX promoter region in a patient with cardiovascular disease, which was associated with a 3-fold reduction in receptor levels on neutrophils compared with individuals with the unaffected allele. There is also a reported association between a FPR2/ALX polymorphism and reduced risk of aspirin hypersensitivity in asthmatics. Patients homozygous for $-4209 \mathrm{~T}>\mathrm{G}$ exhibit a significantly higher expression of FPR2/ALX on monocytes; these individuals are protected from aspirininduced decline in forced expiratory volume [64]. A polymorphism in human MC3R was recently identified in patients suffering from tuberculosis [65], though it remains to be determined if it entails loss of $\mathrm{MC}$ receptor function (hence potential absence of proresolving activities, e.g., safe disposal of bacteria by phagocytosis).

\section{Perspective}

The process termed the 'resolution of inflammation' has recently gained momentum; this entails appreciation of its pathophysiological importance, with (1) the description of mediators (effectors of resolution), (2) the definition of their actions on myeloid cells, and (3) the identification of their receptor targets.

There are now over 20 mediators of resolution, covering families of autacoids, bioactive lipids as well as proteolytically generated peptides and proteins. Over recent years, the definition of an endogenous proresolving mediator has evolved. Inhibition of leukocyte egress from the vasculature into the tissue was originally the main criteria for classification (then referred to as endogenous inhibitors of inflammation) [66]. It is now known that proresolving mediators also regulate antimicrobial defense, apoptosis and efferocytosis as well as monocyte recruitment and myeloid cell egress from the tissue into the lymphatic system. These fundamental processes define not only areas that require further investigation, but also the true dynamic nature of the process of resolution. Furthering our knowledge in this area will produce clear advancements in the pathophysiology of experimental and clinical disease, and together with elucidating the biological behavior of proresolving receptors, will impact on innovative approaches to drug discovery. 
We have reasoned in this review article on the complex nature and biology of FPR2/ALX, chosen as exemplar of proresolving receptors, yet it is important to note that this has not deterred drug development both in terms of LX analogs [67] or the development of selective small molecule agonists by Actelion (e.g., see patent No. WO2010/143158).

We are confident this is still a dawn era in resolution and that the scientific interest in the processes operative in our body to switch off inflammation, and their mediator/receptor pairs, will incite wholehearted involvement of Pharma and Biotechs. It is only with appropriate investment that we can deliver the anti-inflammatory drugs of the next decade, capitalizing on the concept and biology of resolution, and propose the exploitation - in terms of new molecules - of a totally novel approach to the way we consider homeostasis and intervene when this is no longer guaranteed.

\section{Acknowledgements}

Our research is funded by the Arthritis Research UK (Career Development Fellowship 19909) to LVN, Wellcome Trust Programme (086867/Z/08/Z) and Medical Research Council project (MR/K013068/1) grants to MP.

\section{References}

1 Serhan CN, Brain SD, Buckley CD, Gilroy 10 Catania A, Lonati C, Sordi A, Carlin A, LeonDW, Haslett C, O’Neill LA, Perretti M, Rossi AG, Wallace JL: Resolution of inflammation: state of the art, definitions and terms. FASEB J 2007;21:325-332.

- 2 Serhan CN: Lipoxins and aspirin-triggered 15-epi-lipoxins are the first lipid mediators of endogenous anti-inflammation and resolution. Prostaglandins Leukot Essent Fatty Acids 2005;73:141-162.

-3 Levy BD, Clish CB, Schmidt B, Gronert K, Serhan CN: Lipid mediator class switching during acute inflammation: signals in resolution. Nat Immunol 2001;2:612-619.

4 Serhan CN: Resolution phase of inflammation: novel endogenous anti-inflammatory and proresolving lipid mediators and pathways. Annu Rev Immunol 2007;25:101-137.

5 Perretti M, D'Acquisto F: Annexin A1 and glucocorticoids as effectors of the resolution of inflammation. Nat Rev Immunol 2009;9: $62-70$.

6 Damazo AS, Yona S, Flower RJ, Perretti M, Oliani SM: Spatial and temporal profiles for anti-inflammatory gene expression in leukocytes during a resolving model of peritonitis. J Immunol 2006;176:4410-4418.

7 Maderna P, Yona S, Perretti M, Godson C: Modulation of phagocytosis of apoptotic neutrophils by supernatant from dexamethasone-treated macrophages and annexin-derived peptide Ac(2-26). J Immunol 2005; 174: 3727-3733.

8 Leoni G, Patel HB, Sampaio AL, Gavins FN, Murray JF, Grieco P, Getting SJ, Perretti M: Inflamed phenotype of the mesenteric microcirculation of melanocortin type 3 receptornull mice after ischemia-reperfusion. FASEB J 2008;22:4228-4238.

9 Montero-Melendez T, Patel HB, Seed M, Nielsen S, Jonassen TE, Perretti M: The melanocortin agonist AP214 exerts anti-inflammatory and proresolving properties. Am J Pathol 2011;179:259-269. ardi P, Gatti S: The melanocortin system in control of inflammation. Sci World J 2010;10: 1840-1853.

11 Lam CW, Getting SJ, Perretti M: In vitro and in vivo induction of heme oxygenase 1 in mouse macrophages following melanocortin receptor activation. J Immunol 2005;174:2297-2304.

$\checkmark 12$ Soehnlein O, Lindbom L: Phagocyte partnership during the onset and resolution of inflammation. Nat Rev Immunol 2010;10:427-439.

13 Geissmann F, Jung S, Littman DR: Blood monocytes consist of two principal subsets with distinct migratory properties. Immunity 2003;19:71-82.

14 Gordon S, Taylor PR: Monocyte and macrophage heterogeneity. Nat Rev Immunol 2005; 5:953-964.

15 Lominadze G, Powell DW, Luerman GC, Link AJ, Ward RA, McLeish KR: Proteomic analysis of human neutrophil granules. Mol Cell Proteomics 2005;4:1503-1521.

16 Soehnlein O, Zernecke A, Eriksson EE, Rothfuchs AG, Pham CT, Herwald H, Bidzhekov $\mathrm{K}$, Rottenberg ME, Weber C, Lindbom L: Neutrophil secretion products pave the way for inflammatory monocytes. Blood 2008; 112:1461-1471.

17 Maddox JF, Serhan CN: Lipoxin $\mathrm{A}_{4}$ and $\mathrm{B}_{4}$ are potent stimuli for human monocyte migration and adhesion: selective inactivation by dehydrogenation and reduction. J Exp Med 1996;183:137-146.

18 Blume KE, Soeroes S, Keppeler H, Stevanovic S, Kretschmer D, Rautenberg M, Wesselborg S, Lauber K: Cleavage of annexin A1 by ADAM10 during secondary necrosis generates a monocytic 'find-me' signal. J Immunol 2012;188:135-145.

19 Vong L, D’Acquisto F, Pederzoli-Ribeil M, Lavagno L, Flower RJ, Witko-Sarsat V, Perretti M: Annexin 1 cleavage in activated neutrophils: a pivotal role for proteinase 3. J Biol Chem 2007;282:29998-30004.
20 Dalli J, Montero-Melendez T, McArthur S, Perretti M: Annexin A1 N-terminal derived peptide Ac2-26 exerts chemokinetic effects on human neutrophils. Front Pharmacol 2012;3:28.

21 Vago JP, Nogueira CR, Tavares LP, Soriani FM, Lopes F, Russo RC, Pinho V, Teixeira MM, Sousa LP: Annexin A1 modulates natural and glucocorticoid-induced resolution of inflammation by enhancing neutrophil apoptosis. J Leukoc Biol 2012;92:249258.

22 Liu X, Ma B, Malik AB, Tang H, Yang T, Sun B, Wang G, Minshall RD, Li Y, Zhao Y, Ye $\mathrm{RD}, \mathrm{Xu} \mathrm{J}$ : Bidirectional regulation of neutrophil migration by mitogen-activated protein kinases. Nat Immunol 2012;13:457464.

23 Maddox JF, Hachicha M, Takano T, Petasis NA, Fokin VV, Serhan CN: Lipoxin $\mathrm{A}_{4}$ stable analogs are potent mimetics that stimulate human monocytes and THP-1 cells via a Gprotein-linked lipoxin $\mathrm{A}_{4}$ receptor. J Biol Chem 1997;272:6972-6978.

24 Ye RD, Boulay F, Wang JM, Dahlgren C, Gerard C, Parmentier M, Serhan CN, Murphy PM: International union of basic and clinical pharmacology. 73. Nomenclature for the formyl peptide receptor (FPR) family. Pharmacol Rev 2009;61:119-161.

25 Chiang N, Serhan CN, Dahlen SE, Drazen JM, Hay DW, Rovati GE, Shimizu T, Yokomizo T, Brink C: The lipoxin receptor ALX: potent ligand-specific and stereoselective actions in vivo. Pharmacol Rev 2006;58:463-487.

26 Rajagopal S, Rajagopal K, Lefkowitz RJ: Teaching old receptors new tricks: biasing seven-transmembrane receptors. Nat Rev Drug Discov 2010;9:373-386.

27 Krishnamoorthy S, Recchiuti A, Chiang N, Fredman G, Serhan CN: Resolvin D1 receptor stereoselectivity and regulation of inflammation and proresolving microRNAs. Am J Pathol 2012;180:2018-2027. 
-28 Yamada T, Tani Y, Nakanishi H, Taguchi R, Arita M, Arai H: Eosinophils promote resolution of acute peritonitis by producing proresolving mediators in mice. FASEB J 2011;25: 561-568.

29 Isobe Y, Arita M, Matsueda S, Iwamoto R, Fujihara T, Nakanishi H, Taguchi R, Masuda K, Sasaki K, Urabe D, Inoue M, Arai H: Identification and structure determination of novel anti-inflammatory mediator resolvin E3, 17,18-dihydroxyeicosapentaenoic acid. J Biol Chem 2012;287:10525-10534.

- 30 Schwab JM, Chiang N, Arita M, Serhan CN: Resolvin E1 and protectin D1 activate inflammation-resolution programmes. Nature 2007; 447:869-874.

-31 Stables MJ, Shah S, Camon EB, Lovering RC, Newson J, Bystrom J, Farrow S, Gilroy DW: Transcriptomic analyses of murine resolutionphase macrophages. Blood 2011;118:e192e208.

-32 Duffin R, Leitch AE, Fox S, Haslett C, Rossi AG: Targeting granulocyte apoptosis: mechanisms, models, and therapies. Immunol Rev 2010;236:28-40.

-33 El Kebir D, Jozsef L, Khreiss T, Pan W, Petasis NA, Serhan CN, Filep JG: Aspirin-triggered lipoxins override the apoptosis-delaying action of serum amyloid $\mathrm{A}$ in human neutrophils: a novel mechanism for resolution of inflammation. J Immunol 2007;179:616-622.

-34 Godson C, Mitchell S, Harvey K, Petasis NA, Hogg N, Brady HR: Cutting edge: lipoxins rapidly stimulate nonphlogistic phagocytosis of apoptotic neutrophils by monocyte-derived macrophages. J Immunol 2000;164: 1663-1667.

- 35 Scannell M, Flanagan MB, deStefani A, Wynne KJ, Cagney G, Godson C, Maderna P: Annexin-1 and peptide derivatives are released by apoptotic cells and stimulate phagocytosis of apoptotic neutrophils by macrophages. J Immunol 2007;178:4595-4605.

- 36 Titos E, Rius B, Gonzalez-Periz A, Lopez-Vicario C, Moran-Salvador E, Martinez-Clemente M, Arroyo V, Claria J: Resolvin D1 and its precursor docosahexaenoic acid promote resolution of adipose tissue inflammation by eliciting macrophage polarization toward an M2-like phenotype. J Immunol 2011;187:5408-5418.

- 37 Csoka B, Selmeczy Z, Koscso B, Nemeth ZH, Pacher P, Murray PJ, Kepka-Lenhart D, Morris SM Jr, Gause WC, Leibovich SJ, Hasko G: Adenosine promotes alternative macrophage activation via $\mathrm{A} 2 \mathrm{~A}$ and $\mathrm{A} 2 \mathrm{~B}$ receptors. FASEB J 2012;26:376-386.

38 Schif-Zuck S, Gross N, Assi S, Rostoker R, Serhan CN, Ariel A: Saturated-efferocytosis generates pro-resolving CD11b low macrophages: modulation by resolvins and glucocorticoids. Eur J Immunol 2011;41:366-379.

- 39 Gomez IG, Tang J, Wilson CL, Yan W, Heinecke JW, Harlan JM, Raines EW: Metalloproteinase-mediated shedding of integrin beta2 promotes macrophage efflux from inflammatory sites. J Biol Chem 2012;287: 4581-4589.
40 Perretti M, Chiang N, La M, Fierro IM, Marullo S, Getting SJ, Solito E, Serhan CN: Endogenous lipid- and peptide-derived antiinflammatory pathways generated with glucocorticoid and aspirin treatment activate the lipoxin $\mathrm{A}_{4}$ receptor. Nat Med 2002;8:12961302.

41 Ernst S, Lange C, Wilbers A, Goebeler V, Gerke V, Rescher U: An annexin $1 \mathrm{~N}$-terminal peptide activates leukocytes by triggering different members of the formyl peptide receptor family. J Immunol 2004;172:7669-7676.

42 Hayhoe RP, Kamal AM, Solito E, Flower RJ, Cooper D, Perretti M: Annexin 1 and its bioactive peptide inhibit neutrophil-endothelium interactions under flow: indication of distinct receptor involvement. Blood 2006;107: 2123-2130.

43 Gavins FN, Yona S, Kamal AM, Flower RJ, Perretti M: Leukocyte antiadhesive actions of annexin 1: ALXR- and FPR-related anti-inflammatory mechanisms. Blood 2003;101: 4140-4147.

44 Fiore S, Ryeom SW, Weller PF, Serhan CN: Lipoxin recognition sites. Specific binding of labeled lipoxin $\mathrm{A}_{4}$ with human neutrophils. J Biol Chem 1992;267:16168-16176.

45 Chiang N, Fierro IM, Gronert K, Serhan CN Activation of lipoxin $\mathrm{A}(4)$ receptors by aspirin-triggered lipoxins and select peptides evokes ligand-specific responses in inflammation. J Exp Med 2000;191:1197-1208.

46 Bena S, Brancaleone V, Wang JM, Perretti M, Flower RJ: Annexin A1 interaction with the FPR2/ALX receptor: identification of distinct domains and downstream associated signaling. J Biol Chem 2012;287:24690-24697.

47 Dufton N, Hannon R, Brancaleone V, Dalli J, Patel HB, Gray M, D'Acquisto F, Buckingham JC, Perretti M, Flower RJ: Anti-inflammatory role of the murine formyl-peptide receptor 2 : ligand-specific effects on leukocyte responses and experimental inflammation. J Immunol 2010;184:2611-2619.

48 Chen K, Le Y, Liu Y, Gong W, Ying G, Huang J, Yoshimura T, Tessarollo L, Wang JM: A critical role for the $\mathrm{G}$ protein-coupled receptor MFPR2 in airway inflammation and immune responses. J Immunol 2010;184:33313335 .

49 Chen K, Liu M, Liu Y, Yoshimura T, Shen W, Le Y, Durum S, Gong W, Wang C, Gao JL, Murphy PM, Wang JM: Formylpeptide receptor-2 contributes to colonic epithelial homeostasis, inflammation, and tumorigenesis. J Clin Invest 2013.

50 Tae YM, Park HT, Moon HG, Kim YS, Jeon SG, Roh TY, Bae YS, Gho YS, Ryu SH, Kwon HS, Kim YK: Airway activation of formyl peptide receptors inhibits Th1 and Th17 cell responses via inhibition of mediator release from immune and inflammatory cells and maturation of dendritic cells. J Immunol 2012; 188:1799-1808

51 Kim SD, Kim YK, Lee HY, Kim YS, Jeon SG, Baek SH, Song DK, Ryu SH, Bae YS: The agonists of formyl peptide receptors prevent de- velopment of severe sepsis after microbial infection. J Immunol 2010;185:4302-4310.

52 Recchiuti A, Serhan CN: Pro-resolving lipid mediators (SPMs) and their actions in regulating miRNA in novel resolution circuits in inflammation. Front Immunol 2012;3:298.

53 Krishnamoorthy S, Recchiuti A, Chiang N, Yacoubian S, Lee CH, Yang R, Petasis NA, Serhan CN: Resolvin D1 binds human phagocytes with evidence for proresolving receptors. Proc Natl Acad Sci USA 2010;107:16601665.

54 Norling LV, Dalli J, Flower RJ, Serhan CN, Perretti M: Resolvin D1 limits polymorphonuclear leukocyte recruitment to inflammatory loci: receptor-dependent actions. Arterioscler Thromb Vasc Biol 2012;32:1970-1978.

- 55 Morris T, Stables M, Colville-Nash P, Newson J, Bellingan G, de Souza PM, Gilroy DW: Dichotomy in duration and severity of acute inflammatory responses in humans arising from differentially expressed proresolution pathways. Proc Natl Acad Sci USA 2010;107: 8842-8847.

56 Simiele F, Recchiuti A, Mattoscio D, De Luca A, Cianci E, Franchi S, Gatta V, Parolari A, Werba JP, Camera M, Favaloro B, Romano M: Transcriptional regulation of the human FPR2/ALX gene: evidence of a heritable genetic variant that impairs promoter activity. FASEB J 2012;26:1323-1333.

57 Patel HB, Montero-Melendez T, Greco KV, Perretti M: Melanocortin receptors as novel effectors of macrophage responses in inflammation. Front Immunol 2011;2:41.

-58 Patel HB, Bombardieri M, Sampaio AL, D’Acquisto F, Gray M, Grieco P, Getting SJ, Pitzalis C, Perretti M: Anti-inflammatory and antiosteoclastogenesis properties of endogenous melanocortin receptor type 3 in experimental arthritis. FASEB J 2010;24:4835-4843.

-59 Patel HB, Kornerup KN, Sampaio AL, D'Acquisto F, Seed MP, Girol AP, Gray M, Pitzalis C, Oliani SM, Perretti M: The impact of endogenous annexin A1 on glucocorticoid control of inflammatory arthritis. Ann Rheum Dis 2012;71:1872-1880.

60 Cardini S, Dalli J, Fineschi S, Perretti M, Lungarella G, Lucattelli M: Genetic ablation of the FPR1 gene confers protection from smokinginduced lung emphysema in mice. Am J Respir Cell Mol Biol 2012;47:332-339.

61 Matheson M, Rynell AC, McClean M, Berend $\mathrm{N}$ : Cigarette smoking increases neutrophil formyl methionyl leucyl phenylalanine receptor numbers. Chest 2003;123:1642-1646.

62 Stockley RA, Grant RA, Llewellyn-Jones CG, Hill SL, Burnett D: Neutrophil formyl-peptide receptors. Relationship to peptide-induced responses and emphysema. Am J Respir Crit Care Med 1994;149:464-468.

63 Hashimoto A, Hayashi I, Murakami Y, Sato Y, Kitasato H, Matsushita R, Iizuka N, Urabe K, Itoman $\mathrm{M}$, Hirohata $\mathrm{S}$, Endo $\mathrm{H}$ : Antiinflammatory mediator lipoxin $\mathrm{A}_{4}$ and its receptor in synovitis of patients with rheumatoid arthritis. J Rheumatol 2007;34:2144-2153. 
64 Kim HJ, Cho SH, Park JS, Lee TH, Lee EJ, Kim YH, Uh ST, Chung IY, Kim MK, Choi IS, Park BL, Shin HD, Park CS: Association analysis of formyl peptide receptor 2 (FPR2) polymorphisms and aspirin exacerbated respiratory diseases. J Hum Genet 2012;57: 247-253.

65 Cooke GS, Campbell SJ, Bennett S, Lienhardt C, McAdam KP, Sirugo G, Sow O, Gustafson P, Mwangulu F, van Helden P, Fine P, Hoal EG, Hill AV: Mapping of a novel susceptibility locus suggests a role for MC3R and CTSZ in human tuberculosis. Am J Respir Crit Care Med 2008;178:203-207.

66 Perretti M: Endogenous mediators that inhibit the leukocyte-endothelium interaction. Trends Pharmacol Sci 1997;18:418-425.

67 Parkinson JF: Lipoxin and synthetic lipoxin analogs: an overview of anti-inflammatory functions and new concepts in immunomodulation. Inflamm Allergy Drug Targets 2006; 5:91-106.

68 Perretti M, Flower RJ: Modulation of IL-1-induced neutrophil migration by dexamethasone and lipocortin 1. J Immunol 1993;150. 992-999.

69 Serhan CN, Clish CB, Brannon J, Colgan SP, Chiang N, Gronert K: Novel functional sets of lipid-derived mediators with antiinflammatory actions generated from omega- 3 fatty acids via cyclooxygenase 2-nonsteroidal antiinflammatory drugs and transcellular processing. J Exp Med 2000;192:1197-1204.

70 Hong S, Gronert K, Devchand PR, Moussignac RL, Serhan CN: Novel docosatrienes and 17s-resolvins generated from docosahexaenoic acid in murine brain, human blood, and glial cells. Autacoids in anti-inflammation. J Biol Chem 2003;278:14677-14687.

-71 Serhan CN, Yang R, Martinod K, Kasuga K, Pillai PS, Porter TF, Oh SF, Spite M: Maresins: novel macrophage mediators with potent antiinflammatory and proresolving actions. J Exp Med 2009;206:15-23.

72 Yang R, Fredman G, Krishnamoorthy S, Agrawal N, Irimia D, Piomelli D, Serhan CN: Decoding functional metabolomics with docosahexaenoyl ethanolamide (DHEA) identifies novel bioactive signals. J Biol Chem 2011; 286:31532-31541.
3 Nadkarni S, Cooper D, Brancaleone V, Bena S, Perretti M: Activation of the annexin A1 pathway underlies the protective effects exerted by estrogen in polymorphonuclear leukocytes. Arterioscler Thromb Vasc Biol 2011; 31:2749-2759.

74 Hasko G, Linden J, Cronstein B, Pacher P: Adenosine receptors: therapeutic aspects for inflammatory and immune diseases. Nat Rev Drug Discov 2008;7:759-770.

75 El Kebir D, Gjorstrup P, Filep JG: Resolvin E1 promotes phagocytosis-induced neutrophil apoptosis and accelerates resolution of pulmonary inflammation. Proc Natl Acad Sci USA 2012;109:14983-14988.

76 Perretti M, Solito E: Annexin 1 and neutrophil apoptosis. Biochem Soc Trans 2004;32: 507-510.

-77 Weinberger B, Quizon C, Vetrano AM, Archer F, Laskin JD, Laskin DL: Mechanisms mediating reduced responsiveness of neonatal neutrophils to lipoxin $\mathrm{A}_{4}$. Pediatr Res 2008; 64:393-398.

78 Cash JL, Christian AR, Greaves DR: Chemerin peptides promote phagocytosis in a ChemR23- and Syk-dependent manner. J Immunol 2010;184:5315-5324.

79 Koroskenyi K, Duro E, Pallai A, Sarang Z, Kloor D, Ucker DS, Beceiro S, Castrillo A, Chawla A, Ledent CA, Fesus L, Szondy Z: Involvement of adenosine $\mathrm{A} 2 \mathrm{~A}$ receptors in engulfment-dependent apoptotic cell suppression of inflammation. J Immunol 2011;186: 7144-7155.

80 Frasch SC, Berry KZ, Fernandez-Boyanapalli R, Jin HS, Leslie C, Henson PM, Murphy RC, Bratton DL: NADPH oxidase-dependent generation of lysophosphatidylserine enhances clearance of activated and dying neutrophils via G2A. J Biol Chem 2008;283: 33736-33749.

-81 Serhan CN, Dalli J, Karamnov S, Choi A, Park CK, Xu ZZ, Ji RR, Zhu M, Petasis NA: Macrophage proresolving mediator maresin 1 stimulates tissue regeneration and controls pain. FASEB J 2012;26:1755-1765.

82 Liu Y, Cousin JM, Hughes J, Van Damme J, Seckl JR, Haslett C, Dransfield I, Savill J, Rossi AG: Glucocorticoids promote nonphlogistic phagocytosis of apoptotic leukocytes. J Immunol 1999;162:3639-3646.
83 Arita M, Bianchini F, Aliberti J, Sher A, Chiang N, Hong S, Yang R, Petasis NA, Serhan $\mathrm{CN}$ : Stereochemical assignment, antiinflammatory properties, and receptor for the omega-3 lipid mediator resolvin E1. J Exp Med 2005;201:713-722.

84 Cash JL, Hart R, Russ A, Dixon JP, Colledge WH, Doran J, Hendrick AG, Carlton MB, Greaves DR: Synthetic chemerin-derived peptides suppress inflammation through ChemR23. J Exp Med 2008;205:767-775.

85 Dalm VA, van Hagen PM, van Koetsveld PM, Achilefu S, Houtsmuller AB, Pols DH, van der Lely AJ, Lamberts SW, Hofland LJ: Expression of somatostatin, cortistatin, and somatostatin receptors in human monocytes, macrophages, and dendritic cells. Am J Physiol Endocrinol Metab 2003;285:E344-E353.

86 Weinstock JV, Elliott D: The somatostatin immunoregulatory circuit present at sites of chronic inflammation. Eur J Endocrinol 2000; 143(suppl 1):S15-S19.

-87 Blasko E, Haskell CA, Leung S, Gualtieri G, Halks-Miller M, Mahmoudi M, Dennis MK, Prossnitz ER, Karpus WJ, Horuk R: Beneficial role of the GPR30 agonist G-1 in an animal model of multiple sclerosis. J Neuroimmunol 2009;214:67-77.

88 Catania A, Rajora N, Capsoni F, Minonzio F, Star RA, Lipton JM: The neuropeptide alphaMSH has specific receptors on neutrophils and reduces chemotaxis in vitro. Peptides 1996; 17:675-679.

89 Getting SJ, Allcock GH, Flower R, Perretti M: Natural and synthetic agonists of the melanocortin receptor type 3 possess anti-inflammatory properties. J Leukoc Biol 2001;69:98104

90 Frasch SC, Fernandez-Boyanapalli RF, Berry KZ, Leslie CC, Bonventre JV, Murphy RC, Henson PM, Bratton DL: Signaling via macrophage G2A enhances efferocytosis of dying neutrophils by augmentation of RAC activity. J Biol Chem 2011;286:12108-12122.

91 Oh DY, Talukdar S, Bae EJ, Imamura T, Morinaga H, Fan W, Li P, Lu WJ, Watkins SM, Olefsky JM: GPR120 is an omega-3 fatty acid receptor mediating potent anti-inflammatory and insulin-sensitizing effects. Cell 2010;142: 687-698. 